\title{
Menopausal status and severe pathological conditions: is there a place for bone and neuroendocrine markers?
}

\author{
Assist. Prof. Dan Nicolae PADURARU MD PhD ${ }^{1,2}$, Asoc. Prof. Adina GHEMIGIAN MD PhD ${ }^{1,3}$, \\ Assist. Prof. Adriana Elena NICA MD PhD ${ }^{1,2}$, Lecturer Ana VALEA MD PhD ${ }^{4,5}$, \\ Assist. Prof. Mara CARSOTE MD PhD 1,3 \\ 1“C. Davila” University of Medicine and Pharmacy, Bucharest \\ ${ }^{2}$ University Emergency Hospital, Bucharest \\ 3"C. I. Parhon" National Institute of Endocrinology, Bucharest \\ 4"Iuliu Hatieganu" University of Medicine and Pharmacy, Cluj-Napoca \\ ${ }^{5}$ Clinical County Hospital, Cluj-Napoca
}

\begin{abstract}
Introduction. Menopause involves skeletal losses, which may be accelerated by breast cancer and associated therapy, as aromatase inhibitors.

Case presentation. A 67-year old Caucasian female underwent 2 years ago a right mastectomy for breast cancer (invasive ductal carcinoma of mucinous type; 85-90\% positive reaction of estrogen receptor). Synchronously, she presented, at computer tomography, a left adrenal hyperplasia, stationary during follow-up. Tamoxifen was continued for two years, then a switch to anastrozole was done for the last four months. On admission, the assays showed a non-secretor adrenal pattern, with negative neuroendocrine markers, including serum serotonin. Bone profile pointed mild hypercalcemia with normal parathormone levels, as well as bone turnover markers and 25-hydroxyvitamin $D$ (negative imagery scan for bone metastases). Dual-Energy $X$-Ray Absorptiometry (DXA) revealed osteopenia with a mid deterioration of Trabecular Bone Score (TBS) at 1220. Further continuation of aromatase inhibitor is recommended, in association with vitamin D supplementation and monthly oral risendronate, good hydration and serial calcium assays.

Conclusion. Modern approach of menopausal breast cancer with aromatase inhibitors increases the speed of age-related bone loss, while detailed imagery may find otherwise unknown artefacts as non-tumour enlargement of adrenal glands. Whether neuroendocrine markers like 5-hydroxytryptamine will find a place in this particular context, apart from traditional bone indices, is still difficult to establish.
\end{abstract}

Keywords: breast cancer, osteopenia, serotonin

\section{INTRODUCTION}

Menopausal state, either due to a physiological process or surgical intervention, involves a large panel of changes, while the risk of some malignancies is increased (1-3). The management of menopause is complex, being related to a multi-disciplinary team (1-3). Two of the hot topics are represented by high breast cancer incidence after menopause and age-related, as well as estrogen deficiency-associated bone loss, which causes osteoporosis and fragility fractures (4-6).

We aim to introduce a case of a menopausal woman, diagnosed and treated with a mammary malignancy, who was further followed up for 
skeletal status anomalies in a context of unilateral adrenal hyperplasia and an episode of hypercalcemia with normal parathormone levels.

\section{CASE PRESENTATION}

This is a 67-year old non-smoking Caucasian female who was admitted after she had suffered twenty four months ago, a total right mastectomy for breast cancer. The surgical excision and anaesthesia procedures went well, without complications. The pathological report showed invasive ductal carcinoma of mucinous type and immunohistochemistry revealed $85-90 \%$ positive reaction of estrogen receptor, $80-85 \%$ positive reaction of progesterone receptor, negative Cerb B expression, and a value of proliferative index Ki67 of $5-10 \%$. Synchronously, she presented, at computer tomography scan, a left adrenal hyperplasia (an enlargement of the gland that did not associate a well defined mass) and this non-tumoral adrenal aspect was stationary during follow-up. She is known with mild arterial high blood pressure since last decade, which was controlled under adequate drugs. After mammary surgery, therapy with tamoxifen was started and continued for two years, then a switch to anastrozole was done (and she continued it for further four months when she was referred to an endocrinology check-up).

On admission, blood and urinary assays showed a non-secretor adrenal pattern, with negative neuroendocrine markers, including serum serotonin (Table 1). Bone profile pointed mild hypercalcemia with normal parathormone levels, as well as bone turnover markers and 25-hydroxyvitamin D (Table 1). The computer tomography showed stationary aspects without secondary spreading of the malignancy (a similar aspect was described at whole body bone scintigram). Central Dual-Energy X-Ray Absorptiometry (DXA) revealed osteopenia with a mid deterioration of Trabecular Bone Score (TBS) (Figure 1). Further continuation of aromatase inhibitor is recommended, in association with vitamin D supplementation and weekly oral risendronate, good hydration and serial calcium assays.

\section{DISCUSSION}

This female case reflects a strong link between mammary and bone status. Oncologic disease itself, as well as anti-cancer therapy (for instance, aromatase inhibitors), may deteriorate
TABLE 1. Bone parameters, adrenal profile and neuroendocrine markers on a 67-year old female with non-metastatic mammary breast carcicoma, left adrenal enlargement, and menopausal osteopenia during therapy with aromatase inhibitors

\begin{tabular}{|c|c|c|c|}
\hline Parameter & Value & Normal & Units \\
\hline \multicolumn{4}{|c|}{ Neuroendocrine markers } \\
\hline Serotonin & 191 & $80-400$ & $\mathrm{ng} / \mathrm{mL}$ \\
\hline Chromogranin A & 93.5 & $20-125$ & $\mathrm{ng} / \mathrm{mL}$ \\
\hline Neuron specific enolase & 8.51 & $0-12$ & $\mathrm{Ng} / \mathrm{mL}$ \\
\hline \multicolumn{4}{|c|}{ Adrenal profile } \\
\hline Plasma metanephrines & 40.2 & $10-90$ & $\mathrm{pg} / \mathrm{mL}$ \\
\hline Plasma normetanephrines & 173.1 & $20-200$ & $\mathrm{pg} / \mathrm{mL}$ \\
\hline $\begin{array}{l}\text { ACTH (Adrenocorticotrope } \\
\text { Hormone) }\end{array}$ & 8.32 & $3-66$ & $\mathrm{pg} / \mathrm{mL}$ \\
\hline Morning plasma cortisol & 14.03 & $4.82-19.5$ & $\mu \mathrm{g} / \mathrm{dL}$ \\
\hline \multicolumn{4}{|c|}{ Bone indices } \\
\hline Total serum calcium & 10.9 & $8.5-10.2$ & $\mathrm{mg} / \mathrm{dL}$ \\
\hline Ionic serum calcium & 4.51 & $3.9-4.9$ & $\mathrm{mg} / \mathrm{dL}$ \\
\hline Serum phosphorus & 3.2 & $2.3-4.7$ & $\mathrm{mg} / \mathrm{dL}$ \\
\hline 25-hydroxyvitamin D & 33.58 & $30-100$ & $\mathrm{ng} / \mathrm{mL}$ \\
\hline PTH (parathormone) & 51.22 & $15-65$ & $\mathrm{pg} / \mathrm{mL}$ \\
\hline CrossLaps & 0.55 & $0.33-0.782$ & $\mathrm{ng} / \mathrm{mL}$ \\
\hline Osteocalcin & 33.24 & $15-46$ & $\mathrm{ng} / \mathrm{mL}$ \\
\hline P1NP & 41.29 & $15-74$ & $\mathrm{ng} / \mathrm{mL}$ \\
\hline Alkaline phosphatase & 118 & $40-150$ & $U / L$ \\
\hline 24-hours urinary calcium & 0.2 & $0.07-0.3$ & $\mathrm{~g} / 24 \mathrm{hol}$ \\
\hline
\end{tabular}

the skeleton (7). The bone turnover markers are useful for fracture risk assessment, but current guidelines do not routinely recommended their assays, since high inter-individual variations are expected (8). A particular frame is represented by circulating 5-hydroxytryptamine, which serves both as a neuroendocrine marker for neuroendorine neoplasia (NEN) or for breast cancers with neuroendocrine component, as well as atypical bone remodelling indices (9-12). However, controversies still exist in this topic, meaning that it is not well established that non-metastatic NEN cause secondary osteoporosis, neither that routinely assays of blood serotonin will reflect, with high accuracy, its complex skeletal effects $(12,13)$. In this particular case, despite several morbidities as osteopenia and history of mammary carcinoma, the blood bone and neuroendocrine statuses were normal. Hypercalcemia was not confirmed at ionic calcium analysis, neither imagery pointed bone metastases. Most probably, a transient increase of calcium related to hydration status may be involved, since parathromone was normal. The need for paying attention to the skeletal health on menopausal state is well established, but bone loss is accelerated by drugs as anastrozole and a rapid decline is expected unless adequate therapy as vitamin $D$ supplements and 
Practica Medicală - Vol. 11, Nr. 4(48), An 2016
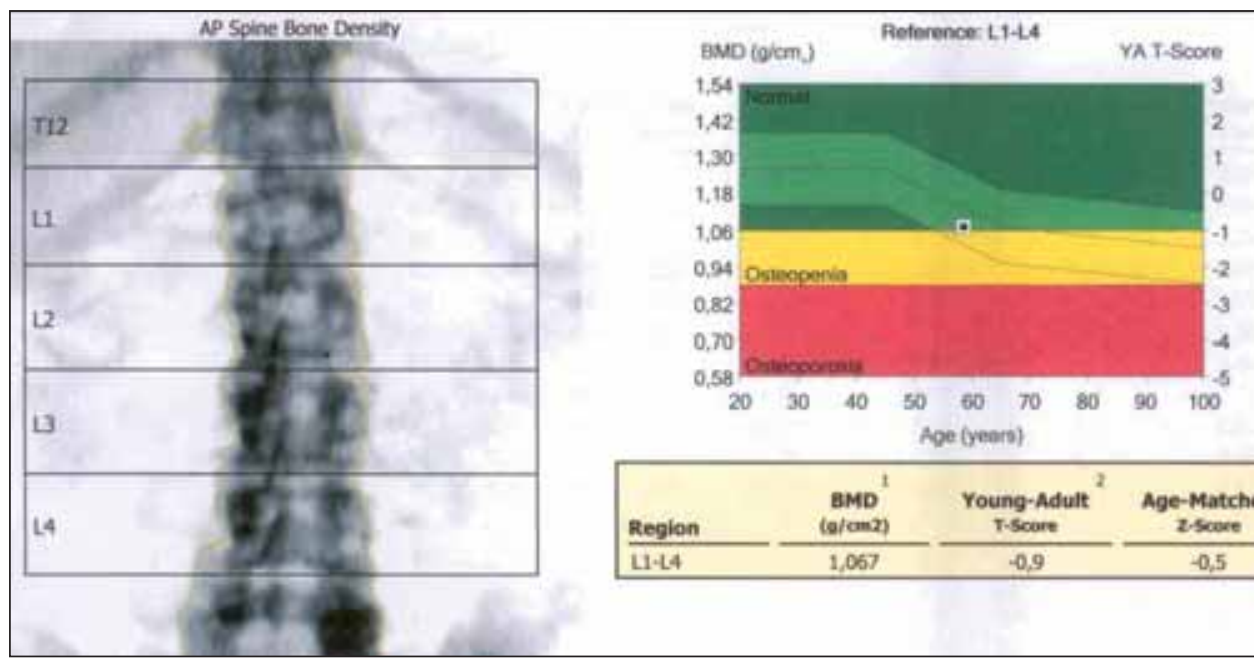

\begin{tabular}{|c|c|c|c|}
\hline Region & $\underset{(\Omega / a n d)}{\operatorname{BMD})^{t}}$ & $\underset{\substack{\text { Young-Adult } \\
\text { T-Soure }}}{2}$ & $\begin{array}{c}\text { Age-Matched } \\
\text { z-scove }\end{array}$ \\
\hline $\mathrm{LI} L 4$ & 1.067 & $-0,9$ & $-0,5$ \\
\hline
\end{tabular}
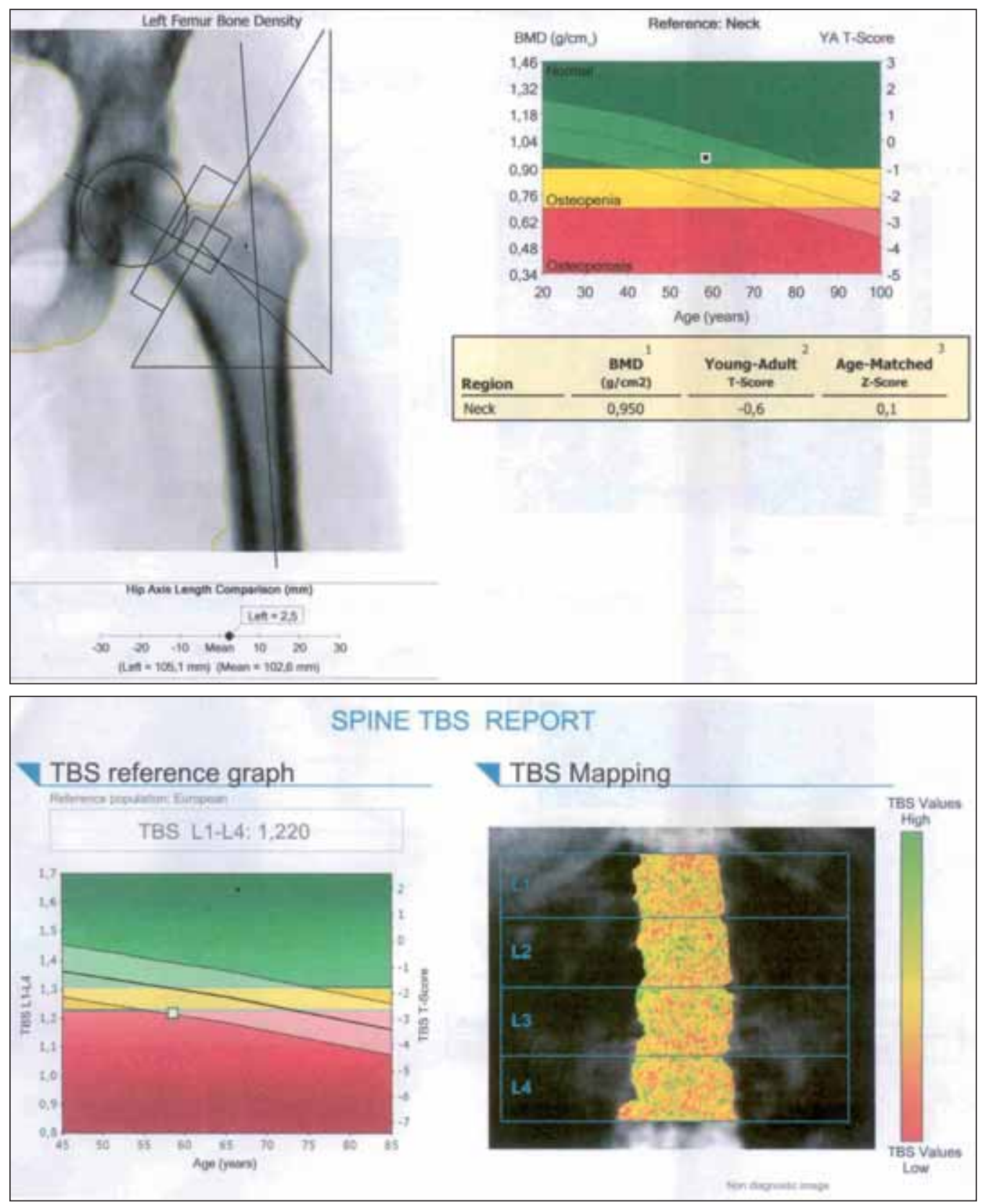

FIGURE 1. Central DXA (Dual-Energy X-Ray Absorptiometry) showing osteopenia on a 67-year female (menopause at age of 50 years) currently under therapy with aromatase inhibitor for a prior breast cancer. A: Lumbar DXA; B: Femoral neck DXA; C: Lumbar DXA-derived Trabecular Bone Score (TBS) 
bisphosphonates is established, as we did in this case (14). We also provided Trabecular Bone Score (TBS), which is the modern tool to evaluate bone micro-architecture, expected to be deteriorated under anastrozole and also on an age-related pattern (our patient showed a mild decrease at the level of 1220 , a normal level been considered above 1350 and a severe deterioration involves a TBS less than 1200) (15).

\section{CONCLUSION}

Modern approach of menopausal breast cancer with aromatase inhibitors increases the speed of bone loss, while detailed imagery may find otherwise unknown artefacts, like non-tumour enlargement of adrenal glands. Whether neuroendocrine markers like 5-hydroxytryptamine will find a place in this particular context, apart from traditional bone indices, is still difficult to establish.

Acknowledgement: This work has been partially supported by Carol Davila UMPh project 33878/11.11.2014/Young researchers

\section{REFERENCES}

1. Lumsden M.A. The NICE Guideline Menopause: diagnosis and management. Climacteric. 2016;19(5):426-9.

2. Lumsden M.A., Davies M., Sarri G. Guideline Development Group for Menopause: Diagnosis and Management (NICE Clinical Guideline No. 23). Diagnosis and Management of Menopause: The National Institute of Health and Care Excellence (NICE) Guideline. JAMA Intern Med. 2016;176(8):1205-6.

3. Stuenkel C.A., Santen R.J. An introduction to the Endocrine Society Clinical Practice Guideline on treatment of symptoms of themenopause. Post Reprod Health. 2016;22(1):6-8.

4. Kruger M.C., Wolber F.M. Osteoporosis: Modern Paradigms for Last Century's Bones. Nutrients. 2016 Jun 17;8(6). pii: E376. doi: 10.3390/nu8060376.

5. Marsden J. The menopause specialist and breast cancer survivorship. Post Reprod Health. 2016 Sep 15. pii: 2053369116668738.

6. Poiana C., Carsote M., Radoi V., Mihai A., Capatina C. Prevalent osteoporotic fractures in 622 obese and non-obese menopausal women. J Med Life. 2015; 8(4):462-6.
7. Kalder M., Hadji P. Breast cancer and osteoporosis - management of cancer treatment-induced bone loss in postmenopausalwomen with breast cancer. Breast Care (Basel). 2014 Oct; 9(5):312-7.

8. Camozzi V., Tossi A., Simoni E., Pagani F., Francucci C.M., Moro L. Role of biochemical markers of bone remodeling in clinical practice. J Endocrinol Invest. 2007; 30(6 Suppl):13-7.

9. Carşote M., Păun S., Neamţu M.C., Avramescu E.T., losif C., Terzea D., Constantinoiu S., Dănciulescu Miulescu R., Neamţu O.M., Poiană C. The immunohistochemistry aspects in two cases of neurofibromatosis-associated abdominal tumors. Rom J Morphol Embryol. 2012; 53(2):401-5.

10. Poiană C., Neamţu M.C., Avramescu E.T., Carşote M., Trifănescu R., Terzea D., Neamţu O.M., Dănciulescu Miulescu R. The dedifferentiation of neuroendocrine tumor metastases: myth or reality? Rom J Morphol Embryol. 2013; 54(1):201-3.

11. Poiană C., Carşote M., Ardeleanu C., Terzea D., Avramescu E.T., Neamţu M.C., Miulescu R.D. The value of the immunohistochemistry in a case of gastric neuroendocrine tumor and thyroid metastasis. Rom J Morphol Embryol. 2011; 52(1):187-92.

12. Poiană C., Carşote M., Neamţu M.C., Avramescu E.T., Vasilescu F., Terzea D., Păun D., Trifănescu R., Dănciulescu Miulescu R. Well-differentiated neuroendocrine tumor and osteoporosis: incidental findings? Rom J Morphol Embryol. 2013; 54(4):1169-71.

13. Carsote M., Radoi V., Geleriu A., Mihai A., Ferechide D., Opris D., Paun D., Poiana C. The serotonin and the bone assessment. J Med Life. 2013 Jun 15; 6(2):151-5.

14. Spangler L., Yu O., Loggers E., Boudreau D.M. Bone mineral density screening among women with a history of breast cancer treated with aromatase inhibitors. J Womens Health (Larchmt). 2013 Feb; 22(2):132-40.

15. Pedrazzoni M., Casola A., Verzicco I., Abbate B., Vescovini R., Sansoni P. Longitudinal changes of trabecular bone score after estrogen deprivation: effect of menopause and aromataseinhibition. J Endocrinol Invest. 2014 Sep; 37(9):871-4. 